PALACIO ARRANZ, Manuel (2019).

\section{Histoire sociale de la télévision en Espagne.}

Lyon: GRIMH.

Una reseña de:

JACOBO HERRERO IZQUIERDO

Universidad de Valladolid

jacoboherrizq@gmail.com
Las particularidades que han acompañado a la televisión desde su nacimiento, sus calificativos como "caleidoscopio social", "ventana al mundo" o incluso "cristal mágico" distancian a esta del resto de medios de comunicación y la presentan, fruto también de su poder de penetración en la audiencia, como instrumento clave para sumergirse y analizar la vida política, económica y cultural de una civilización. La frase lapidaria atribuida al filósofo Gustavo Bueno (2000), "cada pueblo tiene la televisión que merece", encuentra, en la última obra de Manuel Palacio, catedrático de Comunicación Audiovisual y Publicidad en la Universidad Carlos III de Madrid, un interesante matiz que permite reformularla de la siguiente manera: cada pueblo es, en parte, reflejo de su televisión, de sus contenidos y sus transformaciones a lo largo de la historia.

Histoire sociale de la télévision en Espagne (20I9), publicado en la Colección Zoom del Grupo para la reflexión sobre la imagen en el mundo hispánico (Grimh) ofrece una nutrida retrospectiva por las últimas siete décadas de la televisión en España, desde su nacimiento, en octubre de I956, hasta la actualidad más reciente y las series de éxito internacional como La casa de papel (Netflix, 2017-2020). Gracias a un relato que se desarrolla entre esas dos referencias temporales, Palacio ofrece una interesante panorámica, reivindicando la importancia de atender a un patrimonio audiovisual; unas veces olvidado, otras tantas mutilado y en numerosas ocasiones ignoto por la dificultad de acceder a las fuentes.

El monográfico, enmarcado dentro de los estudios sociales y culturales de los mass-media, viene a ser la continuación de otras obras 
relevantes del autor, tales como Historia de la televisión en España (200I) y La televisión durante la transición española (2016), y añade una nueva aportación a las revisiones históricas y políticas sobre el medio televisivo en España (Munsó, 200I; Bustamante, 2013; Montero, 2018). Asimismo, aborda un tema ampliamente examinado en el contexto internacional (Huston, I992; Dilon, 20ıо; Garofallo, 2018), pero que requería de la versión hispana a través de un análisis profundo de los contenidos televisivos que se enriquece con informes del período, artículos periodísticos y testimonios de los profesionales involucrados.

Precisamente, es ese extenso listado bibliográfico y de fuentes documentales, referencias a recortes de prensa y revistas especializadas, estadísticas de audiencias de diferentes años y menciones a programas o emisiones concretas, que acabaron por calar en el imaginario colectivo, lo que permite a Palacio fragmentar la historia de España en el siglo XX y principios del siguiente, convirtiendo al medio televisivo en la herramienta perfecta para zambullirse en las diferentes etapas y explicar el contexto histórico, político y social del momento, siendo esto último el aspecto más desarrollado.

Trabajo ligero en su extensión, pues no llega a superar las doscientas páginas, aunque coherente en cada una de ellas, este título logra ir más allá de un simple repaso sobre la industria televisiva y convierte sus contenidos en algo más que una anécdota, poniendo de manifiesto que si el acto de ver la televisión y los innumerables recuerdos catódicos son de lo más reconocible en la autenticidad de las distintas generaciones, es, en efecto, por esa incapacidad de deslindar la historia de la televisión de la historia general de un país.

Dividido en seis partes, la primera de ellas se sumerge en los orígenes de la cadena estatal en pleno franquismo, surgida como una poderosa herramienta mediática al servicio del régimen, como industria cultural tutelada por el Estado y como instrumento entregado a los intereses de la industria publicitaria que pronto se vería afectado por la tesitura del desarrollismo. Televisión Española se convertiría entonces en un espejo de las contradicciones de la dictadura, a caballo entre el intento de modernización y el necesario aperturismo y las habituales prácticas censoras producto de un país con evidentes carencias democráticas.

En la segunda parte, el libro avanza por ese tardofranquismo de la década de los 60 , con una programación basada eminentemente en los espacios de entretenimiento y donde la vocación disuasoria o "anestesiante" la televisión buscó, en palabras del autor, desideologizar a la población sin desviar la vista del culto a la personalidad del dictador, aunque ya sin el estilo de la tradicional propaganda falangista (p. 2o). De cara al exterior, Televisión Española intentaría llevar el "Spain is diferent" al espacio audiovisual en un intento de aproximación a su entorno europeo que llegaría a su catarsis en el festival de ig68 y el "La, la, la" de la joven Massiel.

El advenimiento de la democracia, que abre la tercera parte de la obra, aborda el rol capital de la televisión en cuanto a instancia legitimadora del sistema de libertades y como "hacedor de democracia" guiada por un objetivo prioritario: consolidar la monarquía. Serán unos años en los que los contenidos audiovisuales establecerán el espacio público nacional y los procesos de identidad común que irían erosionando poco a poco los valores del férreo oficialismo franquista. Nombres propios como el de La Clave (TVE, I976-I985) o Encuentros con las letras (TVE, I976-I98I), de ficciones como 
La Barraca (TVE, I980) o Cañas y barro (TVE, I978), que persiguieron el propósito de desarrollar una pedagogía política a favor de los nuevos valores democráticos, encabezan esta etapa clave de "la tele", en la ésta que fue actor y motor del cambio pese a la permanencia de una censura no regulada.

Posteriormente, el libro se detiene en "la modernización socialista" que sucede al triunfo electoral en I982 del partido de Felipe González, quien aludió a la cadena pública en su discurso de investidura del 30 de noviembre del mismo año. Votar socialismo en las urnas significaba votar un cambio en la televisión, que debía ser "estatal e independiente", según la otra gran voz del partido, Alfonso Guerra, pero que no consiguió deshacer el eterno binomio entre poder y televisión. En este apartado, el autor profundiza en lo que denomina "guerras culturales", que tuvieron como punto de conflicto las representaciones televisivas sobre las cuestiones religiosas, la moralidad o la reinterpretación histórica del pasado: asuntos de desencuentro que harían de las críticas a la programación uno de los principales elementos para ejercer la oposición política.

La Movida, el estilo más rebelde y transgresor visto en espacios como La bola de cristal (TVE, I984 -I988), bajo la dirección de Lolo Rico, o $L a$ edad de oro (TVE, I983 -I985) también encuentran protagonismo en ese periodo relativo a los años 8o, antes de la entrada en escena (o antena, mejor dicho) de la iniciativa privada y la llegada de un nuevo panorama ya sin el monopolio regentado por TVE. Con la creación de los primeros canales privados (Antena 3, Tele 5 y Canal + ) se abre esta nueva fase que recorre los años $90 \mathrm{y}$ el escenario de la libre competencia en el que el espectador, al menos en los primeros años, que- dó sensiblemente desprotegido por la ausencia de un marco jurídico que velase por los derechos del público en el nuevo marco de la globalización.

El autor aprovecha este apartado para ahondar, primero, en el desarrollo de "la televisión de los excesos", representada por Tele 5 de la empresa de comunicación Mediaset, fundada por el magnate italiano Silvio Berlusconi, el cual, de la mano de Valerio Lazarov, se encargaría de llevar a cabo una televisión colorista y desenfada que llegó a traspasar los límites de lo tolerado por la audiencia. Las líneas siguientes prestan atención a la televisión de los "frikis", a la predilección por lo pintoresco y lo extravagante, y la puesta en escena de un histrionismo entre lo patético y lo fascinante ejemplificado a la perfección por el mítico Crónicas Marcianas (Tele 5, I997 - 2005), de Javier Sardá, o por Las noches de tal y tal (Tele 5, I99I), con la emisión para la historia del baño en el jacuzzi del promotor inmobiliario, alcalde de Marbella y presidente del Atlético de Madrid, Jesús Gil, rodeado de mujeres en bikini. La creación de un imaginario erótico a través de las emisiones y la deriva hacia "la televisión basura", como resultado de los programas de telerrealidad, ponen el broche a esos párrafos sobre la televisión noventera, que ya daba señales de fatiga.

La reinvención del modelo audiovisual español, reto que asume la televisión para afrontar su pico de impopularidad en la primera mitad de la década de los noventa, inspira la última parte de esta monografía. La obligada reformulación de los planteamientos base constituyó el mejor aliciente para lo que el autor considera la edad de oro de la televisión española, "probablemente la mejor de su historia” (p. I47), que llega hasta la crisis económica del año 2008. Mediante información sobre los grandes éxitos de audiencia entre I994 y 20I7, Pa- 
lacio consigue dibujar una interesantísima radiografía de la sociedad española contemporánea. Sociedad que se concentró en torno a la sala de estar durante las retransmisiones futbolísticas como la final de la Copa del Mundo, España - Holanda, del año 20ı, o para visualizar el fenómeno de Operación Triunfo, el espacio de variedades más importante de los últimos tiempos y que debe su éxito a la consecución de "un equilibrio perfecto entre el individualismo de la postmodernidad competitiva y el espíritu de grupo de los participantes” (p. I43).

Otros éxitos como las ficciones representativas de género costumbrista -Farmacia de guardia, (Antena 3, I99I-I995), Médico de familia (Tele 5, I995-I999), Cuéntame cómo pasó (TVE, 200I), Aquí no hay quien viva (Antena 3, 2003-2006) - y de tipo histórico-Amar en tiempos revueltos / Amar es para siempre (TVE / Antena 3, 2005), I4 de abril, la República (TVE, 20II), Isabel (TVE, 20I2-20I4), El ministerio del tiempo (TVE, 20I5-20I7), frecuentemente "instrumentalizadas desde el poder para lanzar, directa o indirectamente, políticas concretas" ( $\mathrm{p}$. I58), permiten al lector acercarse a la televisión más actual, siempre a través de un texto ameno y que posibilita un viaje con cierto sabor a nostalgia.

Para concluir, Palacio dedica especial atención al papel de la mujer en la historia social de la televisión, con mención a series como Aida (Tele 5, 2005-2014), El tiempo entre costuras (Antena 3, 20I4), Los misterios de Laura (TVE, 2009-20I4) o Las chicas del cable (Netflix, 20I7), que certifican el mayor interés de la industria televisiva en torno a los personajes femeninos como protagonistas de una ficción audiovisual con una presencia internacional sin precedentes en los últimos años (p.
I68). Esto último, la implantación de nuevas plataformas como Netflix y el impacto de producciones más allá del mercado español, como la antes mencionada La casa de papel, hablan de un nuevo paradigma presentado someramente en este último apartado, y que da pie a futuras investigaciones.

El propio autor reconoce algunos huecos que deja su estudio y que no se llenaron por razones de espacio. Aspectos como el de la televisión autonómica, fundamental en la creación de las identidades regionales, o el relativo los programas matutinos de actualidad política, conformadores de una determinada óptica de pensamiento, no encuentran referencia en este ensayo. Pese a ello, Histoire sociale de la télévision en Espagne (2019) acerca un tema rico y complejo desde una óptica novedosa que dota a la televisión de la justa notoriedad que se merece para comprender con mayor precisión la historia de una civilización en su conjunto.

En esencia, acercarse el medio, a sus éxitos o fracasos es también acercarse a los procesos similares que ocurren en una comunidad, y, por eso, no es de extrañar que el lector o el espectador español tenga más facilidad para conectar con las experiencias e imágenes descritas que alguien ajeno a algo tan propio, tan particular y tan característico como la televisión nacional. Lo anterior, en cualquier caso, no ha de entenderse como un obstáculo, sino como una oportunidad para todo aquel que quiera entender la evolución histórica y sociológica de un país y sus casi setenta años de andanza televisiva. Basta con atender a la infinidad de títulos y protagonistas que se incluyen para confirmar que la obra que aquí se presenta queda lejos de ser algo meramente introductorio. 


\section{BiBLIOGRAFíA}

Bueno Martínez, Gustavo (2002). Telebasura y democracia. Barcelona: Ediciones B.

Bustamante Ramírez, Enrique (2013). Historia de la Radio y la Televisión en España. Una asignatura pendiente de la democracia. Barcelona: Gedisa.

Dillon, Robert (2010). History on British Television: Constructing Nation, Nationality and Collective Memory. Manchester: Manchester University Press.

Garofalo, Damiano (2018). Storia sociale della televisione in Italia (I954 - I969). Venecia: Marsilio.

Huston, A. C. (coord.) (1992). Big world, small screen: The role of television in American society. Lincoln: University of Nebraska Press.

Munsó Cabús, Joan (200I). La otra cara de la televisión:45 años dehistoriaypolítica audiovisual. Barcelona: Flor del Viento Ediciones.

Montero Díaz, Julio (ed.) (20I8). Una televisión con dos cadenas: la programación en España (I956 1990). Madrid: Cátedra

Palacio Arranz, Manuel (200I). Historia de la televisión en España. Barcelona: Gedisa.

Palacio Arranz, Manuel (2016). La televisión durante la transición española La televisión durante la transición española. Madrid: Cátedra. 